\title{
A clinical and genetic study of campomelic dysplasia
}

\author{
S Mansour, C M Hall, M E Pembrey, I D Young
}

\begin{abstract}
Campomelic dysplasia (CMD) is a rare skeletal disorder that is usually lethal. It is characterised by bowing of the lower limbs, severe respiratory distress, and many of the chromosomal (XY) males show sex reversal. Because of a number of reports of familial campomelic dysplasia it is considered to be inherited in an autosomal recessive manner. In this study, details of 36 patients with campomelic dysplasia were collected from genetic centres, radiologists, and pathologists in the United Kingdom. The chromosomal sex ratio was approximately $1: 1$. There was a preponderance of phenotypic females owing to sex reversal. Three quarters of the chromosomal males were sex reversed or had ambiguous genitalia. Three cases are still alive, two with chromosomal rearrangements involving chromosome 17q. The majority of the others died in the neonatal period.
\end{abstract}

The 36 index cases had 41 sibs of whom only two were affected. Formal segregation analysis gave a segregation ratio of 0.05 $(95 \%$ CI $\sim 0.00$ to 0.11$)$. This excludes an autosomal recessive mode of inheritance. The data suggest a sporadic, autosomal dominant mode of inheritance. Patients with a chromosomal rearrangement involving 17q (q23.3-q25.1) show a milder phenotype. The molecular mechanism for the difference is still unknown.

(f Med Genet 1995;32:415-420)

Campomelic dysplasia (CMD) was first described by Maroteaux et $a l^{1}$ in 1971. It is a rare skeletal disorder characterised by bowing of the long bones. The name is derived from campo (or campto), meaning bent, and melia, meaning limb. This "syndrome" has many other skeletal and extraskeletal features. It is frequently lethal in the neonatal period owing to respiratory insufficiency. The reported incidence varies between 0.05 and 1.6 per $10000 .^{2}$

An unusual aspect of CMD is that some patients with male karyotypes have female or ambiguous genitalia with a spectrum of sexual differentiation. ${ }^{3}$ The histology of the ovaries in sex reversed males varies from gonads with testicular differentiation ${ }^{4}$ to dysgenetic gonads with primary follicles. ${ }^{5} \mathrm{CMD}$ is thought to be an autosomal condition as males and females are both affected. Sex reversal of the chromosomal males implies that there is a sex determining gene on an autosome.

There appear to be phenotypic variations of this disorder. Khajavi et $a l^{6}$ described three varieties of campomelic dysplasia. This study will focus on the long limb or classic form of campomelic dysplasia.

The mode of inheritance is controversial. Evidence for autosomal recessive inheritance has been provided by descriptions of pairs of sibs with this condition..$^{7-9}$ However, there are some reports of patients with CMD born to mildly affected parents, ${ }^{111}$ suggesting autosomal dominant inheritance.

Recent interest in CMD has been stimulated by the identification of several cases of what appears to be campomelic dysplasia with chromosomal rearrangements involving chromosome $17 \mathrm{q} .{ }^{12-14}$ It would appear, therefore, that a gene responsible for this condition is located at or close to the breakpoint on chromosome 17q.

\section{Methods}

Clinical, radiological, and pathological data on known or suspected cases of campomelic dysplasia in the United Kingdom were collected and analysed. Forty cases were initially ascertained by contact with clinical geneticists, radiologists, and paediatric pathologists.

Five radiological features were chosen as diagnostic criteria (table 1). These were se-

Table 1 Diagnostic criteria

\section{Radiological}

(1) Hypoplastic scapulae

(2) Bowed femora (marked or mild)

(3) Bowed tibiae (marked or mild)

(4) Vertically narrow iliac wings

(5) Non-mineralised thoracic pedicles

Clinical

Seven or more of the following:

Macrocephaly

Micrognathia

Cleft palate

Flat nasal bridge

Low set ears

Talipes equinovarus

Congenital dislocation of hips

Bowed femora

Bowed tibiae

Pretibial skin dimples

or:

Sex reversal and bowed lower limbs 
Table 2 Frequency of clinical features

\begin{tabular}{lrrrll}
\hline & Yes & No & NS & Total & $\%$ \\
\hline Macrocephaly & 27 & 4 & 5 & $27 / 31$ & 87 \\
Micrognathia & 29 & 2 & 5 & $29 / 31$ & 93 \\
Cleft palate & 19 & 10 & 7 & $19 / 29$ & 66 \\
Flat nasal bridge & 19 & 2 & 15 & $19 / 21$ & 90 \\
Low set ears & 22 & 3 & 11 & $22 / 25$ & 88 \\
Talipes equinovarus & 31 & 2 & 3 & $31 / 33$ & 94 \\
Cong disloc of hips & 23 & 5 & 8 & $23 / 28$ & 82 \\
Bowed femora & 18 & 8 & 10 & $18 / 26$ & 69 \\
Bowed tibiae & 31 & 3 & 2 & $31 / 34$ & 91 \\
Pretibial skin dimples & 22 & 3 & 11 & $22 / 25$ & 88 \\
Respiratory distress & 27 & 1 & 8 & $27 / 28$ & 96 \\
\hline
\end{tabular}

NS $=$ not stated, $\%=$ of those stated

lected on the basis of a review of published reports which indicates that these are the most common and characteristic radiological features in typical CMD cases. Any patient scoring three or more features was included. Many $x$ rays were difficult to score because of poor quality or restricted views. $X$ rays were available for 29 probands and two affected relatives $(n=$ $31)$. In some cases $(n=7)$ no $x$ rays were available, so patients with seven of 11 clinical features were included. Any patients with documented sex reversal and bowed lower limbs were also included. Four cases were excluded from this study because they did not fulfil any of these criteria. This study was therefore based on data from 36 patients.

The amount of clinical information in the case records was variable. The features were scored as present if noted, or observed on photographs or $x$ rays, and absent if specifically commented on. Any feature that was not commented on was classed as not stated (NS). All $x$ rays were reviewed by a single radiologist $(\mathrm{CMH})$ who was unaware of the clinical details. The radiological analysis included all 31 sets of $x$ rays (29 probands, one affected mother, and one affected sib). Necropsy details were available for 22 patients.

\section{STATISTICAL ANALYSIS}

A one sample, two tail Student's $t$ test was used to compare the maternal and paternal ages in this sample with those of the general population in the United Kingdom. This information was obtained from the Office of Population Census records. ${ }^{15}$

Comparison of survival in patients with and without sex reversal was made using a MannWhitney U test.

Segregation analysis was done on the families included. Each family had been ascertained by only one affected person, single incomplete ascertainment. The "sib" method was therefore used to determine the segregation ratio. ${ }^{16}$

Table 3 Necropsy findings

\begin{tabular}{lrrrrr}
\hline & Yes & No & NS & Total & $\%$ \\
\hline Absence of olfactory tract & & & & & \\
or bulb & 1 & 3 & 18 & $1 / 4$ & 25 \\
Hydrocephalus & 2 & 18 & 2 & $2 / 20$ & 10 \\
Congenital heart disease & 5 & 16 & 1 & $5 / 21$ & 22 \\
Tracheomalacia & 5 & 14 & 3 & $5 / 19$ & 26 \\
Small thorax & 12 & 6 & 4 & $12 / 18$ & 67 \\
Renal abnormality & 5 & 17 & 0 & $5 / 22$ & 23 \\
\hline
\end{tabular}

NS $=$ not stated, $\%=$ of those stated.
Table 4 Frequency of radiological findings

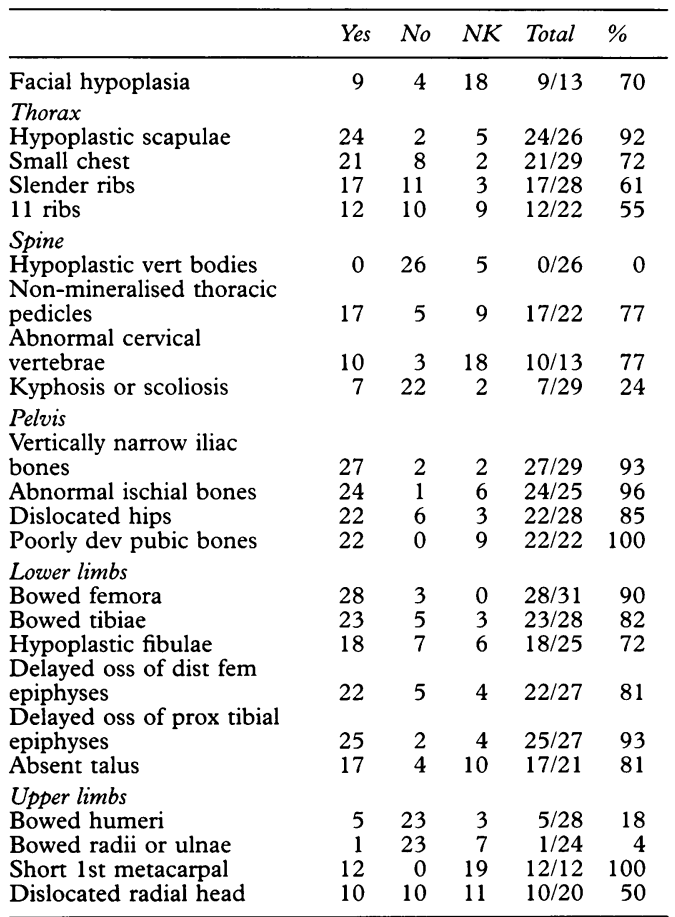

$\mathrm{NK}=$ not known, $\%=$ of those stated.

\section{Results}

The clinical features, necropsy findings, and radiological features are shown in tables 2,3 , and 4 . There was a definite dysmorphic facies with a large dolichocephalic skull, low set ears, flat nasal bridge, hypertelorism, a long philtrum, and micrognathia (fig 1). There was a midline posterior cleft palate in approximately two-thirds of patients in this study.

The radiological features chosen as diagnostic criteria, that is, hypoplastic scapulae, non-mineralised thoracic pedicles, small, vertical iliac bones, and bowed femora and tibiae, occur in high frequency in patients with $\mathrm{CMD}^{3}$ (fig 2). No individual feature is pathognomonic of this condition, but no other syndrome has this combination of features.

In this study, bowing was mainly of the lower limbs, with no or minimal bowing of the humeri, radii, or ulnae. All the patients, in whom it could be determined, had a short first metacarpal.

The femora were, typically, of normal length, width, and density. They were symmetrical and

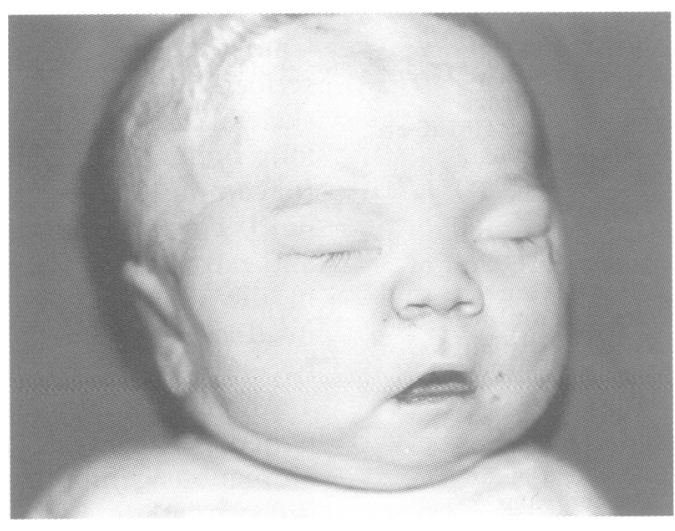

Figure 1 A neonate with campomelic dysplasia showing the typical dysmorphic facies. 


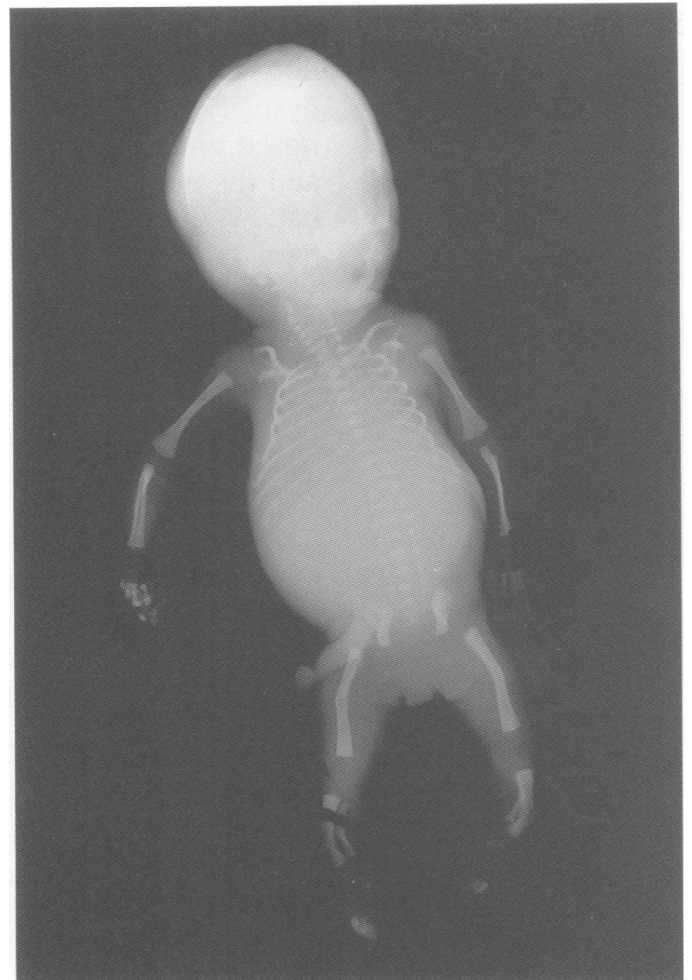

Figure 2 The radiological features of a fetus with campomelic dysplasia, showing hypoplastic scapulae, nonmineralisation of the thoracic pedicles, 11 pairs of ribs, bowed femora, bowed tibiae, and vertical, narrow iliac wings.

Table 5 Mode of delivery

\begin{tabular}{lrrl}
\hline & No & $\%$ & $\begin{array}{l}\% \text { excl } \\
\text { TOPs }\end{array}$ \\
\hline Termination of pregnancy (TOP) & 6 & 19 & - \\
Normal vaginal & 10 & 31 & 38 \\
Forceps & 5 & 16 & 19 \\
Caesarean section & 11 & 34 & 42 \\
\hline
\end{tabular}

sharply angulated between the proximal third and distal two-thirds of the shaft. The tibiae were usually more markedly bowed and associated with hypoplastic fibulae. There was delayed ossification of the distal femoral and proximal tibial epiphyses and the talus. This could only be assessed on the neonatal $x$ rays.

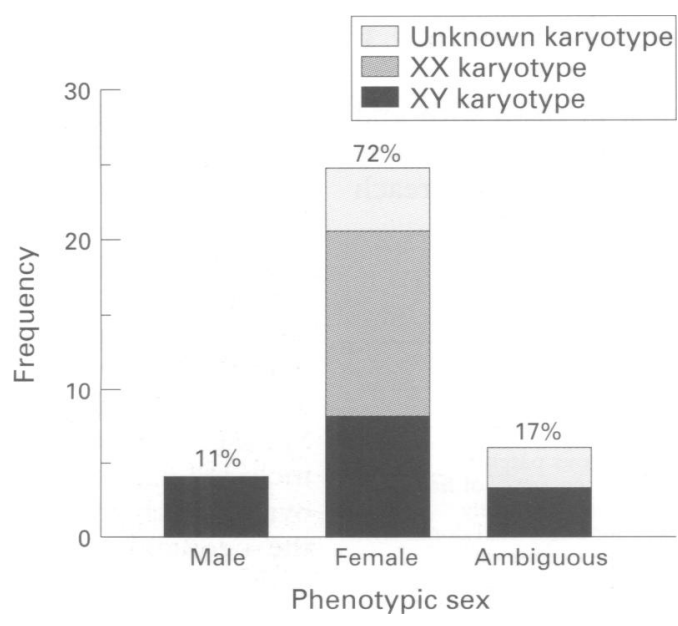

Figure 3 Graph showing frequency of phenotypic sex with karyotype.
The pelvis had a defined appearance with long, vertically narrow iliac and poorly developed pubic bones. There was an increased acetabular angle with a high incidence of dislocated hips (85\%). Many of the pelvic changes could be seen in the older surviving patients.

Over half had only 11 pairs of ribs $(55 \%)$, but these patients had normal segmentation of the spine with six lumbar vertebrae. The cervical vertebrae were frequently abnormal with kyphosis or hypoplastic vertebral bodies (77\%). Non-mineralisation of the thoracic pedicles was associated with abnormally wide lumbar vertebral bodies and pedicles. A kyphosis or scoliosis was not a common finding on neonatal $x$ rays, but featured more frequently in surviving cases. Two of the three survivors had a marked kyphoscoliosis.

PARENTAL AGES AND BIRTH DETAILS

The mean maternal age at delivery was $27 \cdot 3$ years (range $18-39, \mathrm{n}=33$ ). The mean paternal age was 30 years (range $22-43, n=21$ ). The mean year of birth of affected cases was 1987 (range 1977-1994, $\mathrm{n}=36$ ). No statistically significant difference was seen in maternal $(\mathrm{p}=$ $0.87)$ or paternal $(p=0.93)$ age compared to the general population.

Excluding all terminations of pregnancy, the mean gestation at delivery of affected cases was 39.8 weeks (range $36-44, \mathrm{n}=24$ ). The mean birth weight was $3062 \mathrm{~g}$ (range $2040 \mathrm{~g}-4140 \mathrm{~g}$, $\mathrm{n}=21$ ) (10th centile). Polyhydramnios was documented in 12 of 25 pregnancies (48\%).

The mode of delivery is summarised in table 5. The caesarean section (LSCS) rate was $42 \%$, excluding terminations of pregnancy. The rate for LSCS in this study was above the overall population rate in 1987 of $10 \%{ }^{15}$

SEX PHENOTYPE AND GENOTYPE

The frequencies of cases with male, female, and ambiguous external genitalia are summarised in fig 3. The degree of sexual differentiation in the group with ambiguous genitalia varied from bifid scrotum with hypospadias to an enlarged clitoris (fig 4). A karyotype was available on 29 of the patients.

Eight of $22(36 \%)$ of the phenotypic females had an XY karyotype. Eleven of 15 patients $(73 \%)$ with male chromosomes had female or ambiguous genitalia. Fourteen cases had a female karyotype and 15 a male karyotype. Sex reversal with an XX genotype did not occur. All three cases of ambiguous genitalia with a known karyotype were XY.

SURVIVAL

Survival data are shown in table 6. Seventyseven percent, excluding terminations, died in the neonatal period. All died of severe respiratory distress, the majority in the first 24 hours of life. Four patients who survived the neonatal period died before the age of 2 years. There are three patients still alive (patients W, $\mathrm{V}$, and $\mathrm{Z}$ ), of whom two have a chromosomal rearrangement involving chromosome $17 \mathrm{q}$ 


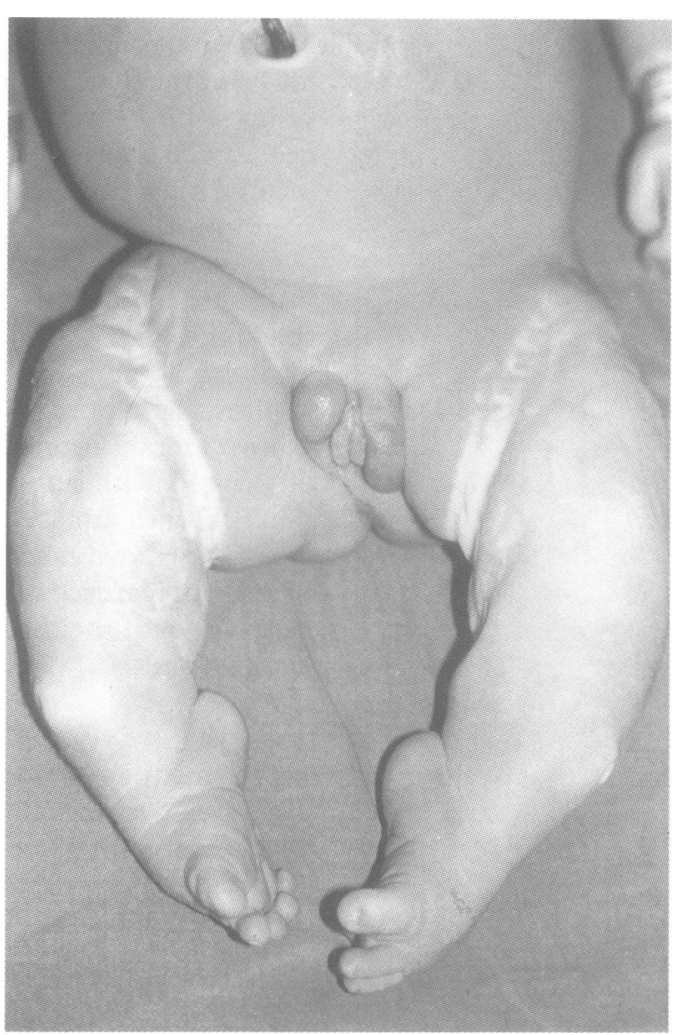

Figure 4 A neonate with campomelic dysplasia, showing ambiguous genitalia, bowing of femora and tibiae, pretibial dimples, and bilateral talipes equinovarus.

Table 6 Age at death, excluding terminations of pregnancy (TOP, $n=6$ )

\begin{tabular}{lrr}
\hline & $N o$ & $\%$ \\
\hline Stillborn & 0 & 0 \\
Neonate & 23 & 77 \\
Infant & 4 & 13 \\
Surviving & 3 & 10 \\
\hline
\end{tabular}

Table 7 Comparison of survival in patients with and without sex reversal (XY karyotypes only)

\begin{tabular}{lll}
\hline Sex reversal & No & Mean age at death (weeks) \\
\hline Yes & 6 & $4 \cdot 83$ \\
No & 5 & $7 \cdot 4$ \\
\hline
\end{tabular}

$\mathrm{p}=0 \cdot 163$, Mann-Whitney $\mathrm{U}$ test.

(patient $\mathrm{V}$ with an inversion 46,XY,inv (17)(q11.2q24.3-25.1) and patient $Z$ had a balanced translocation $46, \mathrm{XX}, \mathrm{t}(4 ; 17)$ (q21.3; q23.3)).

A comparison of survival in cases with and without sex reversal is shown in table 7 . The differences between these groups did not reach statistical significance.

Table 8 Summary of previously reported cases of familial campomelic dysplasia

\begin{tabular}{|c|c|c|}
\hline Reference & Affected sibs & Comments \\
\hline $\begin{array}{l}8 \\
7\end{array}$ & $\begin{array}{l}\text { Affected brother and sister } \\
\text { Two affected sisters }\end{array}$ & \\
\hline 9 & Two affected sibs & Consanguineous parents \\
\hline 3 & Two affected sibs (case 13) & $\begin{array}{l}\text { No } x \text { rays or necropsy of first sib, } \\
\text { diagnosed retrospectively }\end{array}$ \\
\hline 10 & $\begin{array}{l}\text { Two full sibs and one half sib. } \\
\text { Mother had a possible mild } \\
\text { expression of the disorder }\end{array}$ & $\begin{array}{l}\text { Evidence for autosomal dominant } \\
\text { with variable expression, or } \\
\text { gonadal mosiacism in the mother }\end{array}$ \\
\hline 20 & $\begin{array}{l}\text { Two affected sibs, one sex } \\
\text { reversed }\end{array}$ & $\begin{array}{l}\text { Second sib reported as " } x \text { rays not } \\
\text { compatible with CMD" }\end{array}$ \\
\hline 21 & Two affected brothers & Both short limbed variety of CMD \\
\hline 22 & Two affected sibs & Both short limbed variety of CMD \\
\hline
\end{tabular}

\section{INHERITANCE}

Two families had a recurrence of campomelic dysplasia in another offspring. Both were diagnosed antenatally by detailed ultrasound scan and the parents opted for termination of pregnancy. Only one family had consanguinous parents (patient W). There were 38 affected sibs in the 36 sibships and 40 unaffected sibs. Among these unaffected sibs, 19 were born before an affected case and 21 after the first affected case.

Segregation analysis using the "sib method" gave a segregation ratio of $2 / 42=0.05$ (95\% CI 0.00-0.11) (including all sibs).

There may be a rare autosomal recessive form of this condition. The parents of patient W are half first cousins. They have had two affected offspring. Both were XY males and had very similar radiological findings with many features very suggestive of campomelic dysplasia. The pelvis showed the same vertically narrow iliac bones, with the abnormal ischial bones and delayed ossification of the pubis, but neither had dislocation of the hips. They had hypoplastic scapulae but both had 12 pairs of ribs and normal mineralisation of the thoracic pedicles. The femora were markedly bowed and symmetrical but they were curved rather than angulated, short, and broad. Strikingly, there was no bowing of the tibiae and the fibulae were long rather than hypoplastic. It may be that this family belongs to a subgroup of CMD with autosomal recessive inheritance, possibly a unique family as no other similar cases have been identified. However, the mother of these affected sibs is of short stature $(145 \mathrm{~cm})$ and has a mild scoliosis. It is possible that she had a mild expression of the disorder; no skeletal studies have been undertaken.

\section{Discussion}

This study has examined cases of CMD in the United Kingdom over the past 17 years.

\section{CLINICAL FEATURES}

The clinical features seen were similar to those in the cases of Hall and Spranger. ${ }^{17}$ Limb abnormalities featured prominently and were documented in over $80 \%$ of cases. This study found a higher incidence of macrocephaly $(87 \%$ $v 54 \%$ ) and a lower incidence of cleft palate $(66 \%$ v $80 \%)$.

Absence of the olfactory bulbs and tracts has been reported in $50 \%$ of cases. ${ }^{3}$ Unfortunately this was rarely looked for in the 22 necropsies in this study, but was found in one out of four of the patients. Congenital heart disease occurred in $22 \%$ and was usually minor. Three patients had a small, high ventricular septal defect, one had a large atrial septal defect, and one a small pericardial effusion. Hall and Spranger ${ }^{17}$ reported an incidence of $27 \%$, but included patent ductus arteriosus and foramen ovale, which are considered normal findings in the neonatal period. There were no cases of complex or severe congenital heart defects. Five patients $(23 \%)$ had renal abnormalities. All five had hydronephrosis of one or both kidneys with mild to marked pelvicalyceal dilatation. 
Only five of the patients (26\%) had significant macroscopic or histological evidence of tracheomalacia. Many more $(67 \%)$ were described as having a small thorax. This contrasts with the review ${ }^{17}$ which reported a $60 \%$ incidence of tracheomalacia. The findings in this study suggest that the tracheomalacia is only part of the reason these babies encounter severe respiratory distress.

\section{RADIOLOGICAL FEATURES}

These findings correlated well with the review by Hall and Spranger. ${ }^{17}$ However, they found a greater incidence of 11 pairs of ribs $(86 \%$ v $55 \%$ ), abnormal cervical vertebrae $(97 \% v$ $77 \%$ ), but a lower incidence of dislocation of the hips (65\% v 85\%). Their review reported a $100 \%$ incidence of bowed femora and tibiae. Although not commented upon, this may be because of ascertainment bias, that is, the diagnosis was not made unless the patient had bowing of both long bones in the lower limbs. The incidence of bowing in this series was lower $(90 \%$ for bowed femora and $82 \%$ for bowed tibiae) suggesting that bowing of the long bones is not a cardinal feature of CMD. This is supported by previous reports of "acampomelic" campomelic dysplasia. ${ }^{18}$

\section{SEX INCIDENCE AND SURVIVAL}

The incidence of chromosomal male to female affected patients approximated to $1: 1$. This suggests that campomelic dysplasia is probably not an $\mathrm{X}$ linked condition and supports an autosomal mode of inheritance. By including all patients with sex reversal and documentation of bowed lower limbs there will be some ascertainment bias with possibly a higher representation of XY females. Three-quarters of chromosomal males had some disturbance of sexual differentiation. There appeared to be no relationship between sex reversal and prognosis.

The majority of babies died in the neonatal period, most in the first 24 hours. The cause of death was, universally, respiratory distress. Only two cases did not require ventilation at birth. The cause of the respiratory distress is traditionally thought to be severe tracheomalacia; however, there is a large contribution from the small chest, cleft palate, micrognathia, and hypotonia frequently associated with this condition.

\section{PRENATAL DIAGNOSIS}

Six affected fetuses were diagnosed as having a skeletal dysplasia on routine antenatal ultrasound scan. Both recurrences of CMD were detected antenatally. The parents chose to have the pregnancy terminated in all these cases. This shows that ultrasonography can be successfully used for detection of recurrences. One frequent, but non-specific finding was polyhydramnios which was documented in onethird of all the cases. Three of the fetuses had a cystic hygroma which was detected on the antenatal scan.
A notable finding is the high rate of caesarean sections in affected pregnancies, four times higher than the population rate. This emphasises the need for prenatal diagnosis.

\section{INHERITANCE}

For some time, following reports of familial campomelic dysplasia, this condition has been presumed to be autosomal recessive. ${ }^{19}$ However, it has been noted that the number of familial cases observed is less than would be expected in an exclusively autosomal recessive condition. ${ }^{3}$ Some of the reports listed by Houston et $\mathrm{l}^{3}$ were either not suggestive of recessive inheritance $^{10}$ or the cases were not typical of campomelic dysplasia. Table 8 summarises the findings in these case reports. Only three reports describe convincingly the classic long limbed campomelic dysplasia with a family history suggestive of recessive inheritance. In our study, many of the families ascertained through the genetic centres were given an autosomal recessive risk for recurrence $(25 \%)$ and artificial insemination by donor was suggested as an option.

In this study, convincing evidence that CMD is inherited in a dominant manner comes from three observations. The first is the occurrence of a typical case of CMD born to a mildly affected mother ${ }^{11}$ (which has been included in this study). The mother is known to have asymmetrical leg length and it is possible that she has a gonosomal mosiacism for the mutation. Her baby had all the radiological and clinical features of campomelic dysplasia but, despite this, has been listed separately in the latest edition of Mendelian inheritance in man. ${ }^{19}$

The second piece of evidence is the segregation ratio of $0.05(95 \% \mathrm{CI} 0.0-0.12)$ in this study and a low incidence of parental consanguinity $(n=1)$. An autosomal recessive condition would be expected to give a segregation ratio of $0 \cdot 25$. It is possible that this analysis was flawed by incomplete data on other offspring in the families. However, any bias introduced should result in a spuriously high proportion of affected people, that is, recurrences are more likely to be documented than unaffected sibs. Inaccurate diagnoses and genetic heterogeneity which may exist within the group may further complicate the results.

Thirdly, a recent paper describes de novo mutations in one allele of the SOX9 gene on chromosome $17 \mathrm{q}$ resulting in campomelic dysplasia. $^{23}$

This condition is, therefore, probably inherited in an autosomal dominant manner with most cases being the result of sporadic mutations. The relatively small numbers of recurrences are probably because of gonosomal mosaicism in one of the parents. This is supported by two reports of affected half sibs born to apparently normal or mildly affected parents. ${ }^{1024}$

\section{CHROMOSOMAL REARRANGEMENTS}

Two patients in this study, $V$ and $Z$, have chromosomal rearrangements with a break- 
point on $17 \mathrm{q}$. These cases have many features of CMD but with significant differences. They appear to have a much milder phenotype with minimal or no respiratory distress and have, therefore, survived. The long bones of the lower limbs are either mildly bowed or straight. Patient V, a chromosomal male, shows complete sex reversal. A review of published reports shows that these atypical features are common in patients with a translocation or inversion involving chromosome $17 \mathrm{q}(23.3-25.1) .{ }^{14}$ The radiological features are very similar to those in patients with the classic form of campomelic dysplasia with hypoplastic scapulae, 11 pairs of ribs, and the same pelvic changes. All the chromosomal males with $17 \mathrm{q}$ rearrangements show complete sex reversal. Excluding the fetus that was terminated, ${ }^{13}$ only one of the other six died. ${ }^{12}$ The rest are still alive and all have normal intelligence. Four of these patients (including the two in this study) have acampomelic, campomelic dysplasia with no bowing of the long bones but suffer from severe and progressive kyphoscoliosis. Cytogenetically, the breakpoints appear to be closely adjacent at q23-q25. It is speculated that these breakpoints have disrupted a promoter region or exon at the $5^{\prime}$ end of the SOX9 gene. ${ }^{20}$ Full cytogenetic and molecular details of these patients will be reported separately.

\section{Conclusions}

The diagnosis of campomelic dysplasia is established radiologically and the combination of features is characteristic. Strong evidence is provided that campomelic dysplasia is an autosomal dominant condition, although there may be genetic heterogeneity. Patients with chromosomal rearrangements have a milder phenotype and a better prognosis. The authors would like to thank all those who helped with this project: the clinical geneticists, particularly Dr A C Berry, Dr N R Dennis, Professor D Donnai, Dr A E Fryer, Dr C Garrett,
Dr M Gattas, Dr E Hatchwell, Dr J McGaughran, Dr E R Dr M Gattas, Dr E Hatchwell, Dr J McGaughran, Dr E R
Maher, Dr R F Mueller, Dr S Price, Dr J L Tolmie, and Maher, Dr R F Mueller, Dr S Price, Dr J L Tolmie, and
Professor R M Winter; the pathologists, especially Drs A H Gilmour, J W Keeling, Mackenzie, I E Moore, G Mortimer, E R Nairn, $M$ Newbold, F Raafat, V R Sams, $R$ J Scott, and $M$ Seller; the radiologists, Drs H M L Carty, S Chapman, and $M$ D Hendry; the paediatricians, Drs G D Barr, R J Hallett, $H$ Markovitch, G Supramaniam, and R Thomson; and the surgeons, Drs T Bashir, J Carr, M G Hill, and Mr Webb. We would also like to thank Professor David Brook and Dr Marina
Dominguez-Steglich for their work on the molecular aspects. We would especially like to thank the patients and their parents We would also like to thank the skeletal dysplasia group and the Nottingham University Trust fund for financial support.

1 Maroteaux P, Spranger J, Opitz JM, et al. Le syndrome campomelique. Presse Med 1971;79:1157-62.

2 Normann EK, Pedersen JC, Stiris G, et al. Campomelic dysplasia - an underdiagnosed condition? Eur $\mathcal{f}$ Pediatr dysplasia - an unde

3 Houston CS, Opitz JM, Spranger JW, et al. The campomelic syndrome: review, report of 17 cases, and follow-up on the currently 17-year-old boy first reported by Maroteaux et al in 1971. Am f Med Genet 1983;15:3-28.

4 Gardner LI, Assemany SR, Neu RL. XY female: antiandrogenic effect of oral contraceptive? Lancet 1970;ii 667-8.

5 Cooke CT, Mulcahy MT, Cullity GJ, et al. Campomelic dysplasia with sex reversal: morphological and cytogenetic studies of a case. Pathology 1985;17:526-9.

6 Khajavi A, Lachman RS, Rimoin DL, et al. Heterogeneity in the campomelic syndromes: long and short bone varieties. Birth Defects 1976;XII:93-100.

7 Mellows HJ, Pryse-Davies J, Bennett MJ, et al. The camptomelic syndrome in two female siblings. Clin Genet 1980; 18:137-41.

8 Shafai T, Schwartz L. Campomelic syndrome in siblings. $\mathcal{f}$ Pediatr 1976;89:512-3.

9 Winter R, Rosenkranz W, Hofmann H, et al. Prenatal diagnosis of campomelic dysplasia by ultrasonography. Prenat
noter Diagn 1985;5:1-8.

10 Thurmon TF, DeFraites EB, Anderson EE. Familial camptomelic dwarfism. $\mathcal{F}$ Pediatr 1973;83:841-3.

11 Lynch SA, Gaunt ML, Minford AMB. Campomelic dysplasia: evidence of autosomal dominant inheritance. $₹ \mathrm{Med}$ Genet 1993;30:683-6.

12 Maraia $R$, Saal $H$, Wangsa D. A chromosome $17 \mathrm{q}$ de novo paracentric inversion in a patient with campomelic dysplasia; case report and etiologic hypothesis. Clin Genet 1991;39:401-8.

13 Young ID, Zuccollo J, Maltby EL, Broderick NJ. Campomelic dysplasia associated with a de novo $2 \mathrm{q} ; 17 \mathrm{q}$ reciprocal translocation. $f$ Med Genet 1992;29:251-2.

14 Tommerup N, Schempp W, Meinecke P, et al. Assignment of an autosomal sex reversal locus (SRA1) and campomelic dysplasia (CMPD1) to 17q24.3-q25.1. Nature Genet 1993;4:170-4

15 Office of Population Censuses and Surveys. Hospital inpatient enquiry, maternity tables, 1982-5. Series MB4 No 28. Birth statistics. London: HMSO, 1986, 1987.

16 Emery AEH. Methodology in medical genetics. 2nd ed. Edinburgh: Churchill Livingstone, 1986:46-51.

17 Hall BD, Spranger JW. Campomelic dysplasia; further elucidation of a distinct entity. Am $\mathcal{F}$ Dis Child 1980;134: 285-9.

18 Friedrich U, Schaefer E, Meinecke P. Campomelic dysplasia without overt campomelia. Clin Dysmorphol 1992;1:172-8.

19 McKusick V. 211970 and 114290. Camptomelic dwarfism. In: Mendelian inheritance in man. 11 th ed. Baltimore: Johns Hopkins University Press, 1994.

20 Bricarelli FD, Fraccaro M, Lindsten J, et al. Sex-reversed $\mathrm{XY}$ females with campomelic dysplasia are HY negative. Hum Genet 1981;57:15-22.

21 Fryns JP, van den Berghe K, van Assche A, et al. Prenatal diagnosis of campomelic dwarfism. Clin Genet 1981;19: diagnosis

22 Stuve A, Wiedeman $\mathrm{H}$. Congenital bowing of the long bones in two sisters. Lancet 1971;i:495.

23 Foster JW, Dominguez-Steglich M, Guioli S, et al. Campomelic dysplasia and autosomal sex reversal caused by mutations in an SRY-related gene. Nature 1994;372:52530.

24 Ward JC, Gross SJ, Tharapel AT, et al. Report of campomelic dysplasia in paternal half-siblings without apparent consanguinity or parental expression. Am f Hum Genet 1994 3(suppl 55):538A. 